\title{
Comparison of Various Safety Management Systems and Perceptions of Safety Management and Safety Culture in Pakistani Aviation Industry
}

Naeem S*

Pakistan Army Aviation, Riphah International University, Islamabad, Pakistan

\begin{abstract}
This research used industry based survey data for assessing employees perceptions regarding safety culture and safety management specific to aviation industry. Results highlighted that for ensuring safety organizations are of the view that employee's responsibilities towards safety are more essential than to implement safety management system (SMS) effectively and to inspire positive culture towards safety. Research results indicated that engineers involved in aircraft maintenance seemed to be more committed to standard operating procedures (SOPs) and effective organizational procedures/processes in ensuring maintenance system tasks and work. Amusingly, flyers viewed luck as important contributing factor towards safety. Generally, the findings propose the several aviation industry sectors need to do a lot more for ensuring improvement in existing safety culture.
\end{abstract}

Keywords: Aviation; Safety culture; Safety management system (SMS); Luck and safety

\section{Introduction}

According to Ramanujam [1] in numerous ways aviation industry is like other technological advanced, high risk, and closely attached organizations which are working with the vision that 'accidents are inevitable'. Moreover 1980s and 1990s accident investigation reports have provided the road of research for connection between accidents and organizational safety management processes [2-4]. For example, National Transportation Safety Board [5] accident inquiry report of Continental Express Embraer 120 has highlighted that careless approach in hanger clearly indicates that administration did not create an effective and efficient safety orientation for their workers [5]. Therefore emphasizing the requirement to explore other logical, systemic causes that add on to occurrences, mishaps and accidents which corresponds to human error. Practices adopted by organizations which affect the safety systems reliability and performance are the techniques in which safety is ensured in aviation industry: which may lead to either 'safe' or 'careless' safety culture [6]. Safety culture features normally exists in collective organizational behavior of precaution, care, responsibility and concern [7]. Moreover, same safety culture features should be prominent in senior management commitment towards safety [8]. It is also found in the environment which is cordial for sharing important and vital information is also known as 'informed culture', whereas, in 'reporting culture' employees are willing to inform their mistakes, faults, failures and near misses. Moreover, in 'just culture' employees have the faith and trust on their organization and management that they will be dealt impartially and justly [6].

\section{Safety Management Systems and Safety Culture}

Safety management systems in aviation organizations are designed with the understanding that there will always some unsafe acts or safety violations: one of the essential components to ensure safety is to recognize, identify, isolate and manage risks before they results in an accidents. Safety management system effectiveness depends upon how well it is merged in the organizational structure 'the ways in which tasks are accomplished'. Process of safety culture is an ongoing process. Same is created, adopted and ensured as permanent organizational feature. In safety literature of regarding high technological and high risk organizations including aviation industry safety management systems association with safety culture has been argued at length.
Controlling and monitoring authorities are also keen to observe the safety management systems, and safety culture role and their results in ensuring safety. For example, Civil Aviation Authority, United Kingdom [9], has recognized the importance of safety management system and adopted as a methodical, logical risk management linked with flight safety, ground safety and aircraft maintenance to attain higher safety standards. Likewise, Pakistan Civil Aviation Authority is taking measures to enhance flight, ground and maintenance safety standards in aviation industry, as a consequence of concerns raised from 2014 and 2016 'Towards 2017' safety forums. This research highlights the findings of aviation industry in a broader spectrum on how safety is ensured and accomplished in the aviation industry [10]. This research does not offer a comprehensive description of activities related to technicalities of aviation safety. However, this research offers an outline of processes adopted by organizations which affect safety. Specific intents of this research are to evaluate organization's approach towards safety management, to assess safety management systems and safety culture in organizations and also to draw comparison between various safety systems adopted by various countries.

\section{Safety model by professor James Reason}

NASA has adopted the safety model of Professor Reason [6]. He identified the four critical sub-components which interact to create an "Informed Culture", namely a positive Safety Culture that effectively shares information throughout the organization and actively seeks maximum safety. The four key elements (or 'sub-cultures') are defined by Reason as under:-

1. An org climate where people readily report problems, errors and near misses.

*Corresponding author: Naeem S, Pakistan Army Aviation, Riphah International University, Islamabad, Pakistan, Tel: 00923335491914; E-mail: shahzadflyer@yahoo.com

Recieved March 25, 2018; Accepted May 21, 2018; Published May 29, 2018

Citation: Naeem S (2018) Comparison of Various Safety Management Systems and Perceptions of Safety Management and Safety Culture in Pakistani Aviation Industry. J Entrepren Organiz Manag 7: 237. doi: 10.4172/2169-026X.1000237

Copyright: (c) 2018 Naeem S. This is an open-access article distributed under the terms of the Creative Commons Attribution License, which permits unrestricted use, distribution, and reproduction in any medium, provided the original author and source are credited. 
2. An atmosphere of trust where people are encouraged, and even rewarded, for providing safety-related info; and it is clear to everyone what is acceptable and an unacceptable behavior.

3. A culture that can adapt to changing circumstances and demands while maintaining its focus on safety.

4. The willingness and competence to draw the right concl from its safety info and the will to implement maj safety reforms.

\section{Safety Management Strats ${ }^{1}$}

Following safety management strats are being envisioned and practiced in the world:-

1. Reactive (present): Respond to the events, which have already occurred i.e. accidents and incidents.

2. Proactive (present): Actively seeks the identified of hazardous conditions through analysis of the organizational processes.

3. Predictive (future): Analyze sys processes and convert to identify potential future problems.

\section{Relationship between Safety Interferences and Trends}

Before analyzing the safety management concepts, it is important to understand the relationship between safety interference and its effects on ground. Whether and till what extend the safety interference can help towards reduction of accidents. ${ }^{2} \otimes \mathrm{B}$ ased on the data availability since late 1950s, it can be reasonably conclusion that the worldwide accidents rate (included commercial, general and even Armed Forces of the world) among diverse types of flying conditions have dropped impressively. The fact indicates that all aspects of Aviation have benefited from efforts aimed at making the skies safer. However, given the rather dramatic changes evident in accident record, experts believe that it is doubtful that any single intervention was responsible for decline in accident rate. Rather, it is likely the result of variety of factors like advancements in tech, equipment operating procedures and training practices to understand how various interventions have improved Aviation Safety. However, it is an established fact that worldwide accident rates have reduced significantly across all type of diverse flying conditions in relation with the safety interferences undertaken from time to time.

\section{US Navy Experience ${ }^{3}$}

Accident trends in the US Naval Aviation/Marine Corps provide a better insight towards the safety interferences and their effects towards arresting the negative trends in safety and accidents. Several of the safety initiatives within the context of Naval Aviation have been superimposed on the annual accident rate as below. Shappell and Wegmann ${ }^{3}$ believe that despite other factors, there is literal question among naval experts that these intervention played a significant role in the level of safety currently enjoyed by the US Navy/Marine Corps. US Naval Aviation proudly incorporates the graph below in all pub reviews of accidents/mishaps to reflect the safety interferences undertaken and their effects as under:-

${ }^{1}$ An indep Review into the broader issues surrounding the loss of the RAF Nimrod MR2 aircraft XV230 in Afghanistan in 2006 by Charles Haddon- Cave QC, Chapter 17.

${ }^{2}$ Shappell SA, Wegmann DA (2000) The Human Factor Analysis and Classification System. Avn Safety Trends pp: 4.

${ }^{3}$ Shappell SA, Wegmann DA (2000) The Human Factor Analysis and Classification System. Avn Safety Trends pp: 5. a. Early to mid-50s - development of angled carrier deck aboard naval ac carriers.

b. Year 1951 - established of Naval Aviation Safety Centre. For first time, major Command in US Navy was assigned the sole responsibility/authority for monitoring and regulating safety issues in the fleet. Aviation Safety thus elevated to the highest level, as the Safety Centre reported direction to the Chief of Naval Ops.

c. Mid 50s - established of squadron safety program, which included the development of aircrew coordination training and implementation of a periodic human factors review of fleet aviators, which contributed significantly to Naval Aviation Safety by identifying problems and hazards before they result in accidents.

d. Year 1959 - formulation and implementation of Naval Aviation Maintenance Program.

e. Early 1960 - the Replacement Air Group concept was created, requiring pilots to receive specialized training on advanced aircraft before flying in the fleet.

f. Most recently, the established of improved squadron safety program, crew recourse management (CRM), op risk management (ORM) and implementation of periodic human factors review have all contributed significantly to Naval Aviation safety by identifying problems and hazards before they resulted in accidents.

g. As the interferences placed are getting matured, a much lower rate of accidents are observed after 80s, where initially the plateau is achieved and accidents are in process of continuous reduction with every coming year.

h. If the rate of major accidents today is still at level observed in year 1950, over 800 aircraft of US Navy would have been lost in year 2000 alone.

\section{Hel Accidents US/World Experience}

Although civil helicopter sector does not have much parallel with the nature of military employment, however, is useful to strengthen and believe that planned interferences through safety measures lead towards improvements in safety standards and consequently towards reduction in the accidents. After establishment of Intl Hel Safety Team (IHST) ${ }^{4}$ in year 2005 and 10 years coop efforts by the helicopter industry and government safety experts to reverse a negative trend and improve Aviation safety, accident rates have reduced significantly. Prior to establishment of IHST, worldwide civ helicopter accident was rising at rate of 2.5 percent per year. Since 2006 , worldwide helicopter fleet has grown by $30 \%$ but the no of accidents have decreased from $24 \%$ up to $50 \%$ in the world. Accident rate in key nations has decreased with a range of 40 to $60 \%$ during the last 10 years ending 2015 against the baseline 2001-2005. The helicopters accident rates have been slashed by 54\% in US and Europe till the end years' 2015:-

${ }^{4}$ With endorsements from participants of the 2005 Intl Hel Safety Symposium (IHSS), leadership from AHS, HAI, mfrs and other interested orgs, and the U.S Federal Aviation Administration (FAA) joined together to form the Intl Hel Safety Team (IHST). The IHST agreed to dev and implement a data-driven, benefitfocused safety program designed to continuously reduce the risk of hel accidents. It set an aggressive goal of reducing the worldwide helicopter accident rate by $80 \%$ in 10 years (by 2016). 
Years 2015 is as under:-

1. Canada: $33 \%$ decrease in accidents since year 2007.

2. Brazil: $62 \%$ decrease in accidents rate (civ Hel fleet grew by $49 \%$ during the Pd).

3. New Zealand: $43 \%$ decrease in accidents rate since year 2000 .

\section{Why Avn Safety Foremost}

Cost factor ${ }^{5}$ of modern aircraft is enormous, even though these accidents occur less frequently as compared to other type of accidents in the US Navy/Marines. During year 1996 - 2000, loss incurred from Aviation accident alone cost the US Navy/Marines a loss of 3.3 Billion dollars; more than five times as that seen with all other accidents combined. Although correct data in case of Pakistan is not available for comparison, however, it can be arguably concluded that the comparative ratio of cost factor would likely to be close if not the same.

\section{Methodology}

Keeping in view the intricacies in measuring safety management in the aviation sector, a pilot study was carried out in flight training institutions of Pakistan for developing and testing a safety assessment questionnaire. Multiple methodologies used in the pilot study ranging from personal interviews, focus group and detailed analysis of safety instructions, manuals and safety survey reports of related organizations. Moreover, literature study was conducted using journals, periodicals and magazines of Pakistan Civil Aviation Authority, meetings, seminars and speeches of professionals from aviation industry, aviation safety and flight, ground and maintenance safety related academic publications. All collected material and information was used to prepare and develop a questionnaire related to safety assessment which encompassed organizational approach towards safety management, safety culture and safety management systems. The developed questionnaire was pilot tested in aviation and flying training schools. Out of 74 items in the questionnaire, 22 were disregarded due to nonapplicability in the aviation context, low response rate, shared similarity in meaning within items, and lack of relevance to safety assessment. The remaining 52 items were categorized as safety management in relation to aviation industry. The full survey questionnaire included 52 items, selected from the pilot study; same were then divided into two groups. First group consisted of organizational approach towards safety management which had (26 items) and second group consisted of organizational safety management systems and safety culture which also consist of (26 items). Items regarding organizational approach towards safety management mainly focused to gather perception and insight of respondents regarding the role performed by the industry/ organization/corporation in which they are performing their duties, as an individual, to ensure safety. Likewise, items of second group organizational safety management systems and safety culture focused to collect perceptions of respondents on existing safety connected beliefs and attitudes and the techniques in which safety is accomplished in their working organizations. The survey was managed through personal liaison with Pakistan civil aviation authorities, aviation school, flying institutions, pilots, flight operation managers, ground staff and maintenance officers and individuals related to aviation industry in Pakistan. Five hundred twenty filled questionnaires were received, out of which 38 were unusable. Findings of this research are based on 414 questionnaires that were considered valid and properly filled. Though the response rate remained low but still the sample was representative of nearly the complete population of Pakistani aviation

${ }^{5}$ Shappell SA, Wegmann DA (2000) The Human Factor Analysis and Classification System. Avn Safety Trends pp: 8. industry. Respondents of this research represented almost all fields of the aviation industry (Table 1).

\section{Results}

First group consisted of organizational approach towards safety management included 26 items. Second group consisted of organizational safety management systems and safety culture which also consisted of 26 items. Both groups were tested on a 5-point scale where $1=$ strongly disagree and $5=$ strongly agree. Cronbach's Alpha was 0.933 and 0.922 , Kaiser-Meyer-Olkin measure of sampling adequacy was 0.948 and 0.947 and Bartlett's test of Sphericity was significant in both sets of data, highlighting that it was appropriate to use factor analytical method to both data sets. Initial factor solution identified four factors from each data group, basing upon scree plot pattern and decision rule that Eigen values should be higher than or equivalent to one. For determination of factors practical value, two conditions were exercised: First condition was that each item had to surpass 0.4 factor loading, and if loading of any variable is considerably depends upon more than one factor then that variable was incorporated along with that factor which had highest loading factor. First group questionnaire discovered respondent's opinion about organizational approach towards safety management exists in their organizations. Numerous variables were attained from pertinent literature for determination of best safety practices adopted by organizations for management of safety aspects. Pilot test of these best safety practices were carried out for assessment scale optimization of 26 variables. Through factor analysis four factors were removed from the variables Table 2. On first 11 variables, first factor loaded heavily. This factor was named as "positive safety practices". Approximately four-fifth of total difference was enlightened by positive safety practices factor only. Next 6 variables highly correlated with second factor. This factor was named as "safety education". This factor highlights that to ensure safety it is essential to impart safety education. Third factor was named as "implementation of safety (SOPs), policies, instructions and procedures" because next 7 variables were loaded high on this factor. Including last two variables, fourth factor was termed as "personal/individual's safety obligations and responsibilities" because it revealed individual's responsibilities and role towards safety. As reflected in Table 2 these above mentioned four factors accounted for $60.29 \%$ of the difference. As indicated

\begin{tabular}{|l|c|c|}
\hline Core Business of Respondents & Frequency & Percent \\
\hline Maintenance engineering & 73 & \\
\hline Air transport/Airline & 137 & \\
\hline Airport/aerodrome & 18 & \\
\hline Helicopter operations & 25 & \\
\hline Quality assurance/Safety education/exams & 11 & \\
\hline Flight training & 42 & \\
\hline Other-air traffic controla and general aviation & 152 & \\
\hline Total & $\mathbf{4 5 8}$ & $\mathbf{1 0 0}$ \\
\hline Respondents' Position in Organization & Frequency & Percent \\
\hline Pilot & 168 & \\
\hline Maintenance engineer & 78 & \\
\hline Flight training instructor & 45 & \\
\hline Manager & 83 & \\
\hline Personnel, quality assurance/safety education/exams & 25 & \\
\hline Other-air traffic controller and general aviation personnel & 59 & \\
\hline Total & $\mathbf{4 5 8}$ & $\mathbf{1 0 0}$ \\
\hline aCategory air traffic control was combined with general aviation & to preserve \\
\hline confidentiality. & & \\
\hline
\end{tabular}

Table 1: Distribution of surveyor respondents by their business and position in organization/industry. 


\begin{tabular}{|c|c|c|c|c|c|}
\hline \multirow[t]{2}{*}{ Variables } & \multicolumn{5}{|l|}{ Factors } \\
\hline & Your organization & 1 & 2 & 3 & 4 \\
\hline V6 & Takes everyone's safety seriously for whom it is responsible as a document holder & 0.578 & 0.328 & 0.443 & -0.095 \\
\hline V7 & Considers safety-related paperwork essential to ensure everyone's safety & 0.502 & 0.221 & 0.433 & 0.069 \\
\hline V8 & Enforces its safety policies and procedures effectively & 0.628 & 0.432 & 0.357 & -0.088 \\
\hline V10 & Praises those who raise safety concerns & 0.624 & 0.335 & 0.261 & -0.202 \\
\hline V11 & Has a safety officer at hand if and when needed & 0.452 & 0.395 & 0.360 & -0.132 \\
\hline V12 & Takes disciplinary action for non-compliance & 0.538 & 0.350 & -0.055 & 0.162 \\
\hline V13 & Provides adequate resources to ensure safety policy and procedures are followed & 0.563 & 0.369 & 0.421 & -0.126 \\
\hline V14 & Promotes safety through managers/supervisors leading by example & 0.655 & 0.410 & 0.270 & -0.112 \\
\hline V16 & Takes action on the reported safety concerns & 0.683 & 0.193 & 0.376 & -0.149 \\
\hline V17 & Supports staff when they report a situation that can lead to danger & 0.647 & 0.234 & 0.398 & -0.237 \\
\hline V18 & Considers it to be responsible for the safety of its employees and clients. & 0.634 & 0.077 & 0.282 & -0.082 \\
\hline V20 & Ensures that staff attends safety courses and seminars. & 0.161 & 0.759 & 0.321 & -0.072 \\
\hline V21 & Has in-house safety education Programmed. & 0.092 & 0.744 & 0.402 & -0.010 \\
\hline V22 & Ensures all staff are current with regard to safety rules and procedures & 0.369 & 0.705 & 0.278 & -0.027 \\
\hline V23 & Educates staff about the benefits and costs of safety and accidents. & 0.316 & 0.728 & 0.196 & 0.001 \\
\hline V24 & Allows you to practice what you have learned in safety courses and seminars & 0.394 & 0.681 & 0.194 & -0.107 \\
\hline V25 & Considers safety education to be an important part of ensuring safety. & 0.517 & 0.639 & 0.195 & -0.169 \\
\hline V1 & Has incident/accident investigation methods in place & 0.133 & 0.164 & 0.782 & 0.043 \\
\hline V2 & Have safety instructions that are easy to follow. & 0.270 & 0.313 & 0.624 & -0.080 \\
\hline V3 & Has a system in place whereby staff can report incidents anonymously. & 0.172 & 0.248 & 0.460 & -0.072 \\
\hline V4 & Has a safety policy that is non-punitive & 0.293 & 0.111 & 0.618 & -0.251 \\
\hline V5 & Has a practicable safety policy understood by all. & 0.367 & 0.362 & 0.588 & -0.06 \\
\hline V9 & Carries out internal safety audit periodically. & 0.199 & 0.236 & 0.583 & 0.013 \\
\hline V15 & Has a position on 'safety at a reasonable cost' when making crucial decisions & 0.341 & 0.102 & 0.441 & 0.081 \\
\hline V19 & Takes the view that it is up to the individual to ensure own safety & -0.146 & 0.077 & -0.006 & 0.832 \\
\hline \multirow[t]{10}{*}{ V26 } & Considers safety education to be individual staff's responsibility & -0.46 & -0.198 & -0.041 & 0.845 \\
\hline & Variation explained by each factor & & & & \\
\hline & Mean of Factor items & $44.87 \%$ & $6.28 \%$ & $5.25 \%$ & $3.92 \%$ \\
\hline & Total variation explained by these factors & $60.29 \%$ & & & \\
\hline & Cronbach's alpha & 0.9328 & & & \\
\hline & Kaiser-Meyer-Olkin measure of sampling adequacy & 0.944 & & & \\
\hline & Bartlett's tests of sphericity & & & & \\
\hline & Approx. chi-square & 5629.132 & & & \\
\hline & Df & 323 & & & \\
\hline & Significance & 0.000 & & & \\
\hline
\end{tabular}

Table 2: Results of factor analysis of data related to organizations' approach to safety management.

in Table 3, first group data analysis (factors mean) highlighted that respondents are of the opinion that their organization give importance to "individual's safety obligations/responsibilities" (2.95) more significantly in safety management than any other elements. Even though by carrying out pilot study, scale to measure organizational approach towards safety management was established, developed and enhanced. Attribution of factors relative importance is solely because of question's nature and questionnaire wording as highlighted in Table 2. Keeping this in view, it appears that organizations of the respondents give more emphasis towards individual's responsibility towards safety than inculcating positive safety practices and executing safety instruction, policies and SOPs. Whereas, conflicting to this view, aircraft/ground accident investigations highlight that organizational and individual involvement towards safety cannot be detached. Accidents occur as result of joint effect of extended period standing environments, culture of organizations, prevailing working practices, behaviors, customs, attitudes and individual's isolated unsafe actions (Tables 2 and 3) [11,12].

Number two categorized variable 'Safety education' (2.43), highlights that this is regarded important factor towards safety enhancement. Keeping in view first two factors it seems that organizations are alleged to give importance to role of safety education towards safety and therefore ensure its availability using multiple ways. Nevertheless, they had an opinion that it is employer obligation to obtain it and use the same for ensuring own safety in during operations. Respondents had a view that organizations in which they are employed give less emphasis towards safety SOPs, policies instructions procedures and positive safety practices implementation. This employer view may be because organizations assume that employees working in aviation industry should exercise safety as routine affair. If organizations this hypothesis is considered correct then there are chances of employees becoming unworried and complacent towards safety. The variables integrated in above mentioned two factors highlight safety practices such as risk management, resource allocation and monitoring and revising safety SOPs, procedures and policies during operations. Keeping respondents view these factors (18 variables) should be given low priority by their worker, it indicates that not sufficient efforts have been put on at strategic level to ensure safety [7], which exposes organizations for both latent and active failures [6].

Factors related to organizational approach towards safety management and core business and respondent's position

Keeping in view relative significance given to four factors and core business of respondents, businesses related to aircraft maintenance are 


\begin{tabular}{|l|c|c|}
\hline Factors & Means & $\begin{array}{c}\text { Standard } \\
\text { Deviations }\end{array}$ \\
\hline Positive safety practices & 2.23 & 0.82 \\
\hline Safety education & 2.41 & 0.90 \\
\hline Implementation of safety policies and procedures & 2.20 & 0.71 \\
\hline Individual's safety responsibilities & 2.98 & 1.03 \\
\hline
\end{tabular}

Table 3: Means and standard deviations of factors related to organizations approach to safety management.

considered to take "safety education" and "positive safety practices" as the two vital factors in implementation of safety SOPs, practices and procedures. Likewise, keeping in view the respondent's position and four factors it indicates that aircraft maintenance industry assume that their workers think that safety education, positive safety practices and ensuring implementation of safety SOPs, policies, instructions and procedures are vital features ensure safety in aircraft maintenance industry. Keeping this, view aeronautical engineers, aircraft maintenance staffs standout between their coworkers in aviation industry. Moreover, aviation industry and organizations are supposed to give more importance towards implementation of safety SOPs, positive safety practices, policies, instructions, procedures and safety education to their employers for ensuring safety comparing to any other industry. Among aircraft maintenance engineers staffs especially engineers a culture seems to have developed which indicate that they are devoted to ensure safety in their routine maintenance work by intensely following SOPs, policies, instructions and regulatory procedures. $12 \%$ of major aviation occurrences and accidents occurred due to maintenance and inspection shortfalls which is major finding [13]. It is important to know that aircraft accident related to maintenance is on rise [5]. Employees working as air traffic controller and working in aviation industry as general are of the view that their organizations pay more value towards individual's safety responsibility/ obligation than any other aspect. Pilots and air traffic controllers decision-making is based upon the information and statistics received in writing, audio, graphic or visual form demanding a greater judgment level which normally expose them to mistakes although having fully trained and experienced [14,15]. Questionnaire second group gathered respondent's opinions regarding organizational safety culture and safety management systems. Pilot test to optimize scale of 26 variables, attained from organizational positive safety culture and safety management systems literature was conducted. Table 4 indicates 4 vital factors from list of 26 variables and also factor solution. According to views of respondents regarding the ways by which safety is ensured in their industries/organizations on first 16 variables factor 1 loading high. "Organizational positive safety practices and dynamics" can be named as first factor. Only first factor solution has described 3/4 of total variation. On next 3 variables, second factor loading high and was named as "regulator's role". On next 3 variables, factor 3 loaded high was termed as "luck and safety". "Safety management, decision-making and training" was considered as factor 4 , which included last 4 variables. Second group of data factor analysis catered for $61.60 \%$ of explained variation as indicated in Table 4 . Second group of data analysis factors means indicate that respondents seemed 'luck and safety' (3.82) as vital factor highlighting behaviors and beliefs perform an important part in aviation industry safety features Table 5. According to respondents views regulator's role' was rated as number 2 (2.89) highlighting the significance of role of Civil Aviation Authority in implementation of safety. Nevertheless pilot study was carried out for development, assessment and optimization of organizational safety culture and management systems in aviation industry. Relative significance of factors can be credited to the type of questions and questionnaire wording statement as reflected in Table 4 . Interestingly respondents think that luck and safety have more importance as compared with training, positive safety practices and dynamics of industry. An individual may or may not have control but respondent's importance given to luck and safety reflects individuals' behaviors, beliefs and attitudes towards safety. According to Guldenmund [16] such as 'fatalism' this factor configuration is similar to findings of other researchers and 'personal skepticism' [17]. Remarkably, keeping in view safety culture and safety management systems (SMS) factors Table 5 and organizational position of respondents 'flyers/pilots' consider luck and safety as vital factor for safety in aviation. It is prominent to highlight that pilots consider in no circumstances accidents can be prevented whatever anyone does. It is consider by flyers that sooner or later everyone is expected to meet an accident and in aviation industry especially as pilot luck has a major role. This research finding is similar to Australian aviation industry and thus creates similar safety fears that 'when safety culture moves from an individual who believed that it can avert accidents to an individual who agrees accidents to be unavoidable, therefore risk of occurring accidents will rise' [18]. More research work is required to explore whether this particular research finding which highlighted flyer's lack of confidence in existing safety structure or illustrates professional realism of working in an atmosphere which is closely attached communicating systems [1] and is exposed to accidents [6]. 'Regulator's role' was considered as second vital factor suggested that Pakistani aviation industry organizations are assumed to be relying upon Pakistan CAA (Civil Aviation Authority) in connection with implementation of safety. Pakistani Civil Aviation Authority is responsible for establishment of civil aviation flight and ground safety standards, monitoring and compliance to already established standards and provision of search and rescue services throughout Pakistan [19]. Pakistan Civil Aviation Authority is also responsible to conduct incident, occurrence and accident investigations which enhances and modify safety education [20]. Respondents have a view that involvement and participation of Pakistan Civil Aviation Authority has to be authoritative, especially in ensuring the implementation of rules, regulations, procedures and policies regarding aviation. Moreover, Civil Aviation Authority plays a pivotal role as guide in checking, and regulation of aviation safety. "Training, safety management and decision-making" were considered as third strongest element. It is important to highlight that respondents did not identify that in their industries this third factor was considered much important. It can be assumed that aviation industry does not pay ample importance on frequent training and on using latest technology for managing their safety systems. One of the reasons for this may be that safety in aviation industry has a price and cost and the other reason may be that resources needed for training and improvement, and handling safety material might be limited. Variable used to inquire organizational position regarding 'safety measures at realistic cost' might have been observed as puzzling and vague. Weakest factor observed was 'Dynamics of any organization and positive safety drills'. Seemingly, 16 variables were incorporated by this factor. This recommends that in aviation industry, workers do not ponder much on safety linked communications, events, and rehearses. Moreover they do not consider these measures to be of much significance in safety. This factor comprised of variables somewhat related to items described by Diiaz and Cabrera [7] in his safety beliefs investigation, functions required by an organization to ensure operational safety management by Pollitt and Bouckaert [21]. And lastly scale regarding safety climate established by Guldenmund [16]. Keeping contents of this aspect in view, it seems that organizations might be observing safety by not particular safety management systems (SMS) and safety traditional 


\begin{tabular}{|c|c|c|c|c|c|}
\hline \multirow[t]{2}{*}{ Variables } & \multicolumn{5}{|l|}{ Factors } \\
\hline & In your Organizations & 1 & 2 & 3 & 4 \\
\hline V1 & There is an open communication between management and staff about safety issues. & 0.826 & -0.030 & -0.061 & 0.041 \\
\hline V2 & Management usually informs staff of incidents and their outcomes & 0.698 & -0.062 & -0.085 & 0.257 \\
\hline V3 & Safety information is brought to staff's attention by their managers/supervisors & 0.770 & -0.024 & -0.021 & 0.244 \\
\hline V4 & Management takes a personal interest in safety compliance & 0.841 & -0.025 & 0.009 & 0.148 \\
\hline V5 & Even due to financial pressures, safety takes priority & 0.851 & 0.054 & -0.057 & -0.026 \\
\hline V6 & If employee safety is at risk, managers halt operations. & 0.818 & 0.088 & -0.012 & -0.074 \\
\hline V7 & If employee safety is at risk, managers halt operations. & 0.843 & 0.015 & -0.041 & 0.063 \\
\hline V8 & Management encourages fearless reporting of incidents, errors, and safety concerns & 0.806 & 0.161 & 0.065 & 0.102 \\
\hline V10 & Managers have open discussion with employees about safety issues. & 0.801 & -0.052 & 0.041 & 0.166 \\
\hline V11 & Staff does not risk their jobs when they report safety concerns to management & 0.796 & 0.166 & -0.017 & -0.036 \\
\hline V15 & The knowledge gained from incident reviews is usually put into practice & 0.621 & 0.252 & 0.003 & 0.198 \\
\hline V17 & Management allocates resources to meet safety needs & 0.758 & 0.101 & -0.113 & 0.168 \\
\hline V18 & Management knows what goes on in operations & 0.732 & 0.146 & -0.022 & 0.123 \\
\hline V19 & Management does something about hazards before accidents can occur & 0.787 & 0.139 & -0.082 & 0.099 \\
\hline V21 & Most staff receives adequate initial training to confidently do the job & 0.663 & 0.153 & 0.108 & 0.317 \\
\hline V23 & Staff does not face reprisal for raising safety issues. & 0.816 & 0.162 & -0.007 & -0.076 \\
\hline V12 & The regulator's (CAA) rules and policies are clear and simple to follow & 0.055 & 0.822 & 0.034 & 0.017 \\
\hline V13 & CAA's audits are useful in ensuring safety & 0.104 & 0.758 & 0.051 & 0.098 \\
\hline V14 & You are clear about the difference in CAA's safety and enforcement roles. & 0.091 & 0.724 & -0.199 & 0.042 \\
\hline V22 & You believe accidents will happen no matter what anyone does & 0.097 & 0.027 & 0.781 & -0.041 \\
\hline V24 & Staff believes that luck plays a major role in aviation safety & -0.25 & -0.132 & 0.637 & 0.197 \\
\hline V25 & You believe everyone is likely to have an accident sooner or later & 0.005 & -0.025 & 0.831 & -0.156 \\
\hline V9 & Management takes disciplinary action against staff for regulatory noncompliance & 0.386 & 0.071 & 0.176 & 0.426 \\
\hline V16 & You have up-to-date software/technology to manage safety systems & 0.363 & 0.227 & -0.016 & 0.576 \\
\hline V20 & Pilots/engineers receive recurrent training & 0.519 & 0.084 & -0.044 & 0.564 \\
\hline V26 & Judgment of 'safety at a reasonable cost' does not put people at risk & 0.366 & 0.061 & 0.197 & -0.490 \\
\hline \multicolumn{2}{|c|}{ Variation explained by each factor mean of factor items } & $42.54 \%$ & $7.81 \%$ & $6.75 \%$ & $4.83 \%$ \\
\hline & Total variation explained by these factors & $62.60 \%$ & & & \\
\hline & Cronbach's alpha & 0.9230 & & & \\
\hline Kaiser-Mey & in measure of sampling adequacy & 0.948 & & & \\
\hline \multicolumn{6}{|c|}{ Bartlett's tests of sphericity } \\
\hline & Approx. chi-square & 5446.487 & & & \\
\hline & Df & 328 & & & \\
\hline & Significance & 0.000 & & & \\
\hline
\end{tabular}

Table 4: Factor analysis of data related to safety management systems, and safety culture in organizations.

procedures to be essential in safeguarding safety. This research finding is steady with previous observation that workers in aviation industry do pay much attention towards positive safety procedures, practices and application of procedures and policies related to safety Table 3. Seeing four factors and respondent's position, it is worth mentioning that engineers working for aircraft maintenance consider dynamics of organization, safety management training (SMT), safety management system (SMS) and decision making process to be significant factors in safeguarding safety. Likewise, seeing four factors and core business of respondents, it is obvious that engineering sector related to aircraft maintenance is professed to consider dynamics of organization and safety management training (SMT) safety, management system (SMS) and decision making process to be serious apparatuses in managing safety in the type of work they perform. In short, engineering workers involved in aircraft maintenance regard dynamics of organization and safety management system (SMS) highly important in managing safety (Tables 4 and 5).

\section{Conclusions}

This research highlighted employee's perceptions regarding aviation safety culture and safety management in aviation industry basing upon two data sets. Firstly organizations' attitude towards safety management having (26 variables) and safety management system

\section{Factors}

Means Standard

Organizational dynamics and positive safety practices

Regulator's role

Luck and safety

Safety management, training and decision making

\section{Deviations}

0.86

$3.81 \quad 0.84$

$2.68 \quad 0.75$

Table 5: Means and standard deviations of factors related to safety management systems (SMS), and safety culture in aviation industries.

(SMS), and organizational safety culture (26 variables). For assessment of safety management in aviation organizations, through pilot study a calculation scale was established and optimized for every data set. Both data sets were imperiled to factor analysis and appeared results to have acceptable inner reliability. The other interesting finding of this research was that pilots consider "Luck and Safety" as the most vital factor towards aviation safety. Individual's working as quality inspectors, imparting safety education and responsible for safety examinations also have similar views. For establishment whether there is any lack of confidence on safety provision system or that workers just perform their task with the idea and knowledge that in aviation safety is dependent upon good/bad luck there is a need for further research. Major finding of this research was that workers working in aviation industry are not seemed to be paying much importance towards organizational aviation safety culture and safety management system (SMS), particularly 
Citation: Naeem S (2018) Comparison of Various Safety Management Systems and Perceptions of Safety Management and Safety Culture in Pakistani Aviation Industry. J Entrepren Organiz Manag 7: 237. doi: 10.4172/2169-026X.1000237

and air traffic control (ATC), overall aviation sector and airport sector. Seemingly, they assume this as an individual's obligation. Moreover, safety to be given more importance than safety teaching, positive safety procedures and implementation of safety procedures, SOPs, instructions and policies. Furthermore, findings highlight that aviation organization does not respect safety training, management, and decision-making process of much significance in managing and ensuring safety. This might be less wanted keeping in view shortage of resources for funding such events and to promote safety culture having positive effects. In reality, only engineers related to aircraft maintenance gives safety culture, safety management system (SMS) much significance. The other important finding is that employers do not pay much importance towards safety related procedures and processes, events and structures such as regular training, having latest technology for management of safety information. Moreover, they do not have a position towards the awareness regarding "Safety at a rational cost". However, Pakistani civil aviation authorities' participation, particularly in relation to aviation rules, regulations, procedures and policies, examining and their role as a mentor and supervisor was considered authoritative. Finally, this research has provided a comparison between various organizations and a synopsis of employees view regarding how safety is accomplished in aviation industry. Basing upon findings of this research, it can be established that organizations in numerous industry sectors could perform better in handling safety and can improve safety culture. It is suggested that several sectors work in collaboration with civil aviation authority (CAA) for improvement of safety in aviation industry. Further research work is required to explore and excavate deeper into the aspects and issues raised in this research.

\section{References}

1. Ramanujam R (2003) The effects of discontinuous change on latent errors in organizations: The moderating role of risk. Acad Manage J 46: 608-617.

2. Wiener EL, Nagel DC (1988) Human factors in aviation. Academic Press.

3. Grove EJ (2014) The Royal Navy since 1815: A new short history. Palgrave Macmillan.

4. Dekker S (2014) The field guide to understanding human error. Ash gate Publishing, Ltd

5. McDonald N, Corrigan S, Daly C, Cromie S (2000) Safety management systems and National Transportation Safety Board, 1992. Aircraft Accident Report: Continental Express Flight 2574 In-flight Structural Breakup, EMB-120RT, N33701, Eagle Lake, Texas (NTSB/AAR-92/04), National Transportation Safety Board, Washington DC. Safety culture in aircraft maintenance organizations. Saf Sci 34: 151-176.

6. Reason J (1997) Managing the risks of organizational accidents. Routledge

7. Diaz RI, Cabrera DD (1997) Safety climate and attitude as evaluation measures of organizational safety. Accid Anal Prev 29: 643-650.

8. Gill GK, Shergill GS (2004) Perceptions of safety management and safety culture in the aviation industry in New Zealand. J Air Transp Manag 10: 231-237.

9. Civil Aviation Authority of United Kingdom (2002) Safety Management Systems for Commercial Air Transport Operations.

10. Liou JJH, Tzeng GH, Chang HC (2007) Airline safety measurement using a hybrid model. J Air Transp Manag 13: 243-249.

11. Hoff KA, Bashir M (2015) Trust in automation: Integrating empirical evidence on factors that influence trust. Hum Factors 57: 407-434.

12. Maurino DE, Reason J, Johnston N, Lee RB (2017) Beyond aviation human factors: Safety in high technology systems. Routledge.

13. Chang YH, Wang YC (2010) significant human risk factors in aircraft maintenance technicians. Saf Sci 48: 54-62.

14. Dagdeviren M, Yuksel I (2008) Developing a fuzzy analytic hierarchy process (AHP) model for behavior-based safety management. Inf Sci 178: 1717-1733.

15. Dias LFA (2010) comparative study of the perceptions of risk of public safety aviation helicopter pilots with the reality of the accidents of these aircraft 2010 University of Brasilia.

16. Guldenmund FW (2000) The nature of safety culture: a review of theory and research. Saf Sci 34: 215-257.

17. Glendon AI, Clarke SG, McKenna EF (2016) Human safety and risk management. CRC Press.

18. Fox SJ (2017) Mobility and movement are our fundamental rights. Safety \& security-risk, choice \& conflict! Issues in Aviation Law and Policy.

19. Civil Aviation Authority of Pakistan (1999) Aviation safety regulation - a decade of change. Civil Aviation Authority of Pakistan.

20. Civil Aviation Authority of Pakistan (2000) Profile 2000: Safety in partnership with the aviation industry for Pakistan. Civil Aviation Authority of Pakistan.

21. Pollitt C, Bouckaert G (2004) Public Management Reform: A Comparative Analysis. Oxford University Press. 